\title{
Evaluation of conservative management of uncomplicated acute appendicitis in a rural medical college
}

\author{
Hazarika Devid', Barua PP2 \\ Received on October 25, 2018; editorial approval on December 15, 2018.
}

\begin{abstract}
Introduction: Acute appendicitis is one of the commonest causes of acute abdomen with life time risk of 7-8\%. Currently appendectomy is the favored treatment for acute appendicitis. However, there is wide discussion and controversy on the surgical and nonsurgical treatment of acute uncomplicated appendicitis. Objectives: The study was conducted to evaluate the efficacy and outcomes of the conservative management of uncomplicated cases of acute appendicitis. Materials and methods: The study was done in department of surgery, Fakhruddin Ali Ahmed Medical College and Hospital, Barpeta, Assam, india, a rural medical college \& hospital from January 2014 to December 2016. Patients above the age of 16 yrs with clinical and radiological features of acute appendicitis presenting within 72 hrs of the beginning of abdominal pain were included. All patients received broadspectrum antibiotics and symptomatic treatment. The followup period was 1 year. Patients were informed to report immediately if symptoms reappear or patients underwent appendectomy outside. Results: out of the 45 patients evaluated, 27(60\%) patients were female and 18 (40\%) patients were male with mean age 34 years. Conservative treatment was effective in 34(75.5\%) patients and failure encountered in 11(24.4\%) patients. No mortality recorded in this study. The main complications which occurred in those patients who failed to respond to conservative treatment were perforated appendicitis (1 patient), appendicular abscess (1 patient) and appendicular lump (2 patients). Conclusion: selected cases of uncomplicated acute appendicitis can be treated successfully by conservative treatment. However, conservative treatment needs close monitoring and followup along with proper communication to the patient.
\end{abstract}

Keywords: Efficacy; antibiotics; nonsurgical treatment; appendectomy.

\section{INTRODUCTION}

Acute appendicitis is one of the commonest cause of acute abdomen in general surgery practice. Complications of appendicitis include perforation and generalized peritonitis. Currently, appendectomy has been the primary treatment in most cases. ${ }^{1}$ However, in $10 \%$ of cases the appendix is found to be normal. ${ }^{1,2,3}$ Appendectomy can result in many complications such as surgical wound infection, intestinal obstruction due to adhesions, tubal infertility in females and rarely fistula. Non operative management with antibiotics may be a cost-effective alternative to surgery in a large percentage of patients without increasing the risk and may reduce hospital stay and costs in both developed and third world countries. ${ }^{4}$ There is considerable discussion regarding the application of conservative treatment compared with surgical treatment in selected cases of acute appendicitis, as few studies have addressed this issue to date. ${ }^{5,6}$ Some reports state that immediate appendectomy can be avoided for at least $24 \mathrm{hrs}$ without increasing morbidity if antibiotics are administered. ${ }^{7,8}$ Other authors suggest that appendectomy may not be necessary for the majority of patients with acute uncomplicated appendicitis, as the condition resolves spontaneously without the need for a surgical procedure in

\footnotetext{
Address for correspondence:

${ }^{1}$ Assistant Professor,

Department of Surgery, Assam Medical College, Dibrugarh, Assam, India.

Email: drdevidgmc@gmail.com

Mobile:+919127754570

${ }^{2}$ Associate Professor (Corresponding Author)

Department of Surgery, Fakhruddin Ali Ahmed Medical College and Hospital, Barpeta, Assam, India.

Email: ppbarua22@gmail.com

Mobile:+919435149330
} 
many patients and in others may be treatable with antibiotics alone. ${ }^{9}$ This approach has many advantages, including high success and low recurrence rates, reduced morbidity and mortality, less pain, shorter hospitalization and sick leave, and reduced costs. ${ }^{10}$ The aim of this study was to evaluate the effectiveness of conservative treatment in uncomplicated acute appendicitis using antibiotics.

\section{MATERIAL AND METHODS}

This prospective study was carried out in Fakhruddin Ali Ahmed Medical College between January 2014 to December 2016. Selected 45 patients were enrolled in this study based on the inclusion and exclusion criteria. All patients above 16 years of age with a history of pain in right iliac fossa for less than $72 \mathrm{hrs}$ and clinically diagnosed as the first attack of appendicitis were included in this study. Ultrasound of abdomen was done for all patients to confirm the clinical diagnosis of acute appendicitis. Patients having perforation, abscess, lump on clinical examination and radiological reports were excluded along with patients unwilling for conservative management. All patients meeting the inclusion criteria then admitted to the hospital and received intravenous antibiotics (cefotaxime $1 \mathrm{~g}$ twice daily and metronidazole infusion 500 $\mathrm{mg} / 100 \mathrm{ml} 3$ times per day) for 5 days along with intravenous fluids, no oral intake with 6 hourly charts for temperature, blood pressure, pulse rate, respiratory rate and local abdominal sign. Patients who did not respond to conservative treatment or worsened were operated by appendectomy. Patients were told to contact immediately if pain recurs, vomiting and fever had occurred. Follow-up was done for one year at interval of three months. Patients were told to inform us if they underwent an operation outside.

Statistical analysis: Statistical package for social science version 20 (SPSS 20) was used for both data entry and data analysis. Discrete variable presented as number (\%). Chisquare test (or fisher exact test when appropriate) used to test the significance of association for the discrete variable. p-value of $<0.05$ were considered significant.

\section{RESULTS}

Out of 45 cases 27 patients were female and 18 patients were male (Figure 1). Age distribution is shown in Table 1. Age ranged between 16 and 60 years. The maximum number of patients (42\%) belonged to age group 20-29 years. $30(66.6 \%)$ patients presented with signs and symptoms of acute appendicitis to the hospital with time interval $<24$ hrs, $8(17.7 \%)$ patients presented with time interval $24-48$ hrs and $7(15.5 \%)$ patients presented with time interval 48-72 hrs as shown in Table 2. Out of 45 patients, $34(75.5 \%)$ patients were successfully managed with conservatively. In the remaining $1(24.4 \%)$ patients, conservative treatment failed. Failure to respond to treatment was seen in 5 patients $(11 \%)$ during initial admission whereas recurrence was seen in 6 patients (13.3\%) cases during follow up period (Figure 2).

Of the 11 patients who failed to respond to conservative treatment, 5 patients were operated after 2 days of treatment,

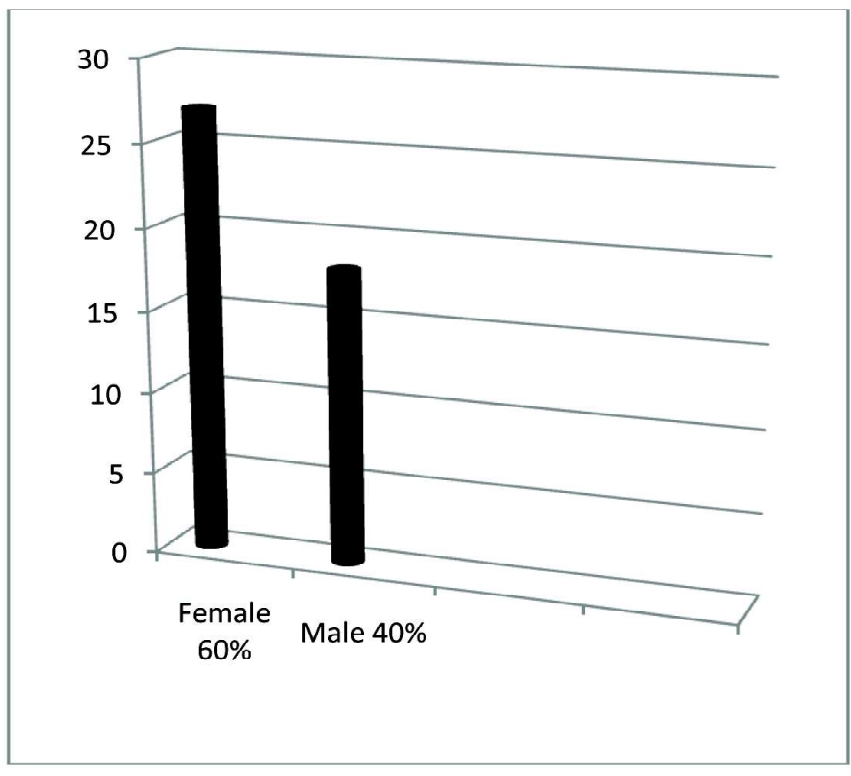

Figure 1 Sex distribution of the study

Table 1 Age distribution of the study

\begin{tabular}{|l|l|}
\hline Age (years) & No. of patients (\%) \\
\hline$<19$ & $3(6.6)$ \\
\hline $20-29$ & $19(42.2)$ \\
\hline $30-39$ & $12(26.6)$ \\
\hline $40-49$ & $9(20)$ \\
\hline$>50$ & $2(4.4)$ \\
\hline Total & $\mathbf{4 5 ( 1 0 0 )}$ \\
\hline
\end{tabular}

Table 2 Number of the patients according to the duration of presenting symptoms

\begin{tabular}{|l|l|}
\hline $\begin{array}{l}\text { Hours of attack of } \\
\text { appendicitis }\end{array}$ & No. of the patients (\%) \\
\hline$<24 \mathrm{~h}$ & $30(66.6)$ \\
\hline $24-48 \mathrm{~h}$ & $8(17.7)$ \\
\hline $48-72 \mathrm{~h}$ & $7(15.5)$ \\
\hline Total & $\mathbf{4 5 ( 1 0 0 )}$ \\
\hline
\end{tabular}

2 patients were operated after completion of treatment course after 7 days and 4 patients were operated during the followup period of 1 year as shown in Table 3. Among the operated patients, 1 patient had perforated appendix, 1 patient had appendicular abscess and 2 patients had appendicular lumps.

\section{DISCUSSION}

Appendectomy has been regarded as the gold standard for treatment of acute appendicitis. The mortality rate of appendectomy ranges from 0.07 to 0.7 and from 0.5 to 2.4 without and with perforation, respectively. Antibiotic 


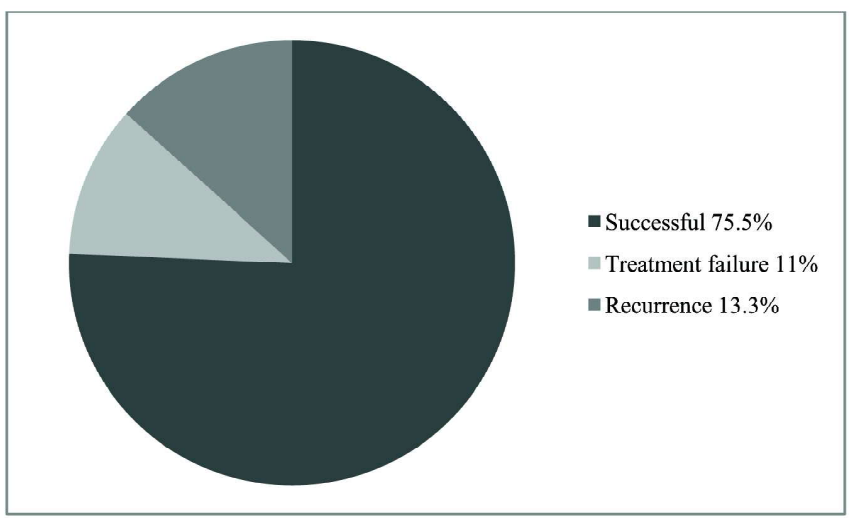

Figure 2 Outcome of conservative treatment

Table 3 Appendectomies after trial of conservative treatment

\begin{tabular}{|l|l|}
\hline Time of interval appendectomy & No. of the patients $(\mathbf{n}=\mathbf{1 1})$ \\
\hline Surgery after 48 h of treatment & 5 \\
\hline $\begin{array}{l}\text { Appendectomy after } 7 \text { days } \\
\text { of treatment }\end{array}$ & 2 \\
\hline Appendectomy within 1 year & 4 \\
\hline
\end{tabular}

treatment can reduce the mortality and morbidity risk associated with surgery. Antibiotics give the chance to treat acute appendicitis when surgical means are not readily accessible particularly in rural areas of developing countries and isolated areas. Conservative treatment is associated with less cost effect balanced to surgery. ${ }^{11}$

In the present study, 34 patients out of 45 patients were successfully treated with conservative method and 5 patients (11\%) failed to respond to conservative treatment and had been operated and further 6 patients $(13.3 \%)$ showed recurrence of appendicitis during the follow-up period. Thus 11 patients failed to respond and the failure rate was $24.4 \%$. In a similar study done in Sahlgrenska University Hospital (between May 2009 and February 2010) involving 442 patients show that 342 patients $(77.4 \%)$ treated conservatively successfully and 100 patients $(22.6 \%)$ failed to respond to conservative treatment, ${ }^{12}$ which nearly resemble our study results. Another study which was done in the surgical department of GMERS Medical College, Gandhinagar between years 2011-2013, that involve a sample of 30 patients undergoing conservative management show that 21 patients $(70 \%)$ treated conservatively successfully and 9 patients $(30 \%)$ failed to respond conservatively. ${ }^{13}$ Our study results also agree with a recent study done in India in 2016 by Gedam PS. Et al which involved 71 patients and showed a successful rate $74.65 \%$, treatment failure rate $14.08 \%$ and recurrence rate $13.11 .^{14}$ We used third generation cephalosporin and metronidazole in all our patients, similar to most randomized control trials.

\section{CONCLUSION}

Conservative treatment can be applied safely in the majority of cases of the first attack of uncomplicated acute appendicitis, avoiding appendectomy and its associated morbidity and mortality. However, conservative treatment needs close monitoring and follow up of the patients. Treatment failure after conservative treatment is of low incidence and acceptable to the patient.

Ethical clearance: Taken.

Conflict of interest: No conflict of interest associated with this work

\section{Source of funding: None.}

Contribution of Authors: We declared that this work was done by the authors named in this article and all liabilities pertaining to claims relating to the content of this article will be borne by the authors.

\section{REFERENCES}

1. Addiss DG, Shaffer N, Fowler BS, Tauxe RV. The epidemiology of appendicitis and appendectomy in US. Am J Epidemiol 1990;132:910-23.

2. Raja AS, Wright C, Sodickson AD, Zane RD, Schiff GD, Hanson $R$, et al. Negative appendectomy rate in era of CT: An 18-year perspective. Radiology 2010;256(2):460-5.

3. Colson M Skinner, Dunnington G. High negative appendectomy rates are no longer acceptable. Am J Surg 1997;174:723-7.

4. Subramanian A, Liang MK. A 60-year literature review of stump appendicitis: the need for a critical view. Am J Surg 2012;203:503-7.

5. Ansaloni L, Catena F, Coccolini F, Ercolani G, Gazzotti F, Pasqualini E, et al. Surgery versus conservative antibiotic treatment in acute appendicitis: a systematic review and metaanalysis of randomized controlled trials. Dig Surg 2011;28:21021.

6. Styrud J, Eriksson S, Nilsson I, Ahlberg G, Haapaniemi S, Neovius G, et al. Appendectomy versus antibiotic treatment in acute appendicitis. A prospective multicenter randomized controlled trial. World J Surg 2006;30(6):1033-7.

7. Shindoh J, Niwa H, Kawai K, Ohata K, Ishihara Y, Takabayashi $\mathrm{N}$, et al. Predictive factors for negative outcomes in initial nonoperative management of suspected appendicitis. J Gastrointest Surg 2010;14(2):309-14.

8. Liu K, Fogg L. Use of antibiotics alone for treatment of uncomplicated acute appendicitis: a systematic review and metaanalysis. Surgery 2011;150:673-83.

9. Mason RJ. Surgery for appendicitis: is it necessary? Surg Infect Larchmt 2008;9(4):481-8.

10. Sakorafas GH, Mastoraki A, Lappas C, Sampanis D, Danias N, Smyrniotis V, et al. Conservative treatment of acute appendicitis: heresy or an effective and acceptable alternative to surgery? Eur J Gastroenterol Hepatol 2011;23(2):121-7.

11. Hansson J, Korner U, Khorram-Manesh A, Solberg A, Lundholm $\mathrm{K}$. Randomized clinical trial of antibiotic therapy versus appendicectomy as primary treatment of acute appendicitis in unselected patients. Br J Surg 2009;96(5):473-81.

12. Hansson J, Korner U, Ludwigs K, Johnsson E, Jonsson C, Lundholm K. Antibiotics as first-line therapy for acute appendicitis: evidence for a change in clinical practice. World $\mathbf{J}$ Surg 2012;36(9):2028-36.

13. Vaishnav U, Chauhan H. Evaluation of conservative management of acute appendicitis in tertiary care hospital. IAIM 2016;3(2):41-4.

14. Gedam BS, Gujela A, Bansod PY, Akhta M. Study of conservative treatment in uncomplicated acute appendicitis. Int Surg J 2017;4(4):1409-16. 